\title{
Incretin as a Pathophysiological Component and Target for Treatment in Youth Type 2 Diabetes (T2D)
}

\author{
Jordan Jacob, Jared Rosenberg, \& Joon Young Kim \\ Syracuse University
}

\section{Introduction}

\begin{abstract}
Incretin hormones have recently been considered an important pathophysiological factor for T2D in adults and youth due to their role in augmenting insulin secretion (Michaliszyn et al., 2014). It is recognized that glucagon-like peptide-1 (GLP-1) and glucose-dependent insulinotropic peptide (GIP) are glucose-dependent hormones released from the gut that stimulate insulin release from pancreatic $\beta$-cells (Muscelli et al., 2006). Thus, the insulin response to oral glucose is significantly greater than the intravenous (IV) glucose administration response; this is known as the incretin effect (Michaliszyn et al., 2014). To date, adults with T2D demonstrate a remarkable decrease in the incretin effect (Nauck et al., 1986), whereas there is lack of evidence in pediatric populations. The incretin effect is also associated with $\beta$-cell glucose sensitivity ( $\beta C G S$ ), attesting incretins as a high-promising target for T2D treatment (Michaliszyn et al., 2014). Utilizing GLP-1 receptor agonists can be advantageous as a therapeutic option for both adults and youth (Tamborlane et al., 2019; Vanderheiden et al., 2016; Yeow et al., 2017).
\end{abstract}

Keywords: Youth-onset type 2 diabetes, incretin effect, glucagon-like peptide-1

$\begin{array}{lr}\text { Article History } & \begin{array}{r}\text { Corresponding Author } \\ \text { Received } 18 \text { September } 2020\end{array} \\ \text { Accepted } 23 \text { October } 2020 & \text { Joon Young Kim } \\ \text { Publim291@syr.edu } & \text { j1 October } 2020 \\ \text { Available online 31 December 2020 } & \text { Department of Exercise Science } \\ \text { https://doi.org/10.47544/johsk.2020.1.1.24 } & \text { The David B. Falk College of Sport and Human Dynamics } \\ \text { Syracuse University, USA }\end{array}$

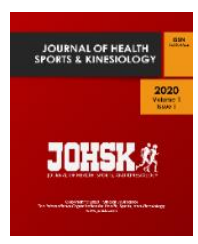

\section{Overview}

Literature has consistently described that a core defect in the pathogenesis of T2D is pancreatic $\beta$-cell dysfunction against the backdrop of insulin resistance (Michaliszyn et al., 2014). It is proposed that incretins enhance insulin release by sensitizing pancreatic $\beta$-cells to glucose (Michaliszyn et al., 2014; Muscelli et al., 2006). Thus, incretin defect could contribute to the $\beta$-cell dysfunction, which is considered the most powerful metabolic predictor of T2D, and the mechanisms surrounding a decreasing incretin effect have been explored in recent literature (Michaliszyn et al., 2014).

\section{Journal of Health Sports \& Kinesiology | ISSN 2692-9864 | www.johsk.com}


| 2020 | Volume 1 | Issue 1 | The Journal of Health, Sports, and Kinesiology |

Evidence has consistently demonstrated a reduced, and sometimes even absent, incretin effect in adults with T2D (Nauck et al., 1986). The incretin effect has been quantitated as the percent difference or ratio between the insulin response seen during an oral glucose tolerance test (OGTT) in relation to IV glucose administration (Muscelli, et al., 2006; Nauck et al., 1986). During an OGTT, adults with T2D exhibited a significantly reduced (36\%) incretin contribution to the total insulin response compared to healthy adults who demonstrated a $73 \%$ incretin contribution in response to oral glucose challenges (Nauck, et al., 1986). Despite no clear difference in the incretin effect observed between adults with normal glucose tolerance (NGT) vs. impaired glucose tolerance (IGT), the incretin effect on potentiation (i.e., the phenomenon encompassing glucose-induced and incretin-induced potentiation of insulin release) differs significantly (Figure 1), emphasizing potential contribution of incretin defects from NGT to IGT (Muscelli, et al., 2006). Specifically, in IGT adults, a significant rise in GLP-1 corresponded with a flat, unresponsive time course of potentiation following an OGTT, whereas adults with NGT expressed a rise in potentiation in correspondence to an increase in GLP-1 (Figure 1) (Muscelli, et al., 2006).

To our knowledge, data regarding the incretin effect in IGT and T2D are sparse in pediatrics. One pediatric study showed that obese adolescents have a reduced incretin effect (estimated by the ratio OGTT-

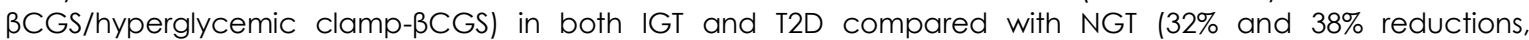
respectively), with no difference between IGT and T2D (Michaliszyn et al., 2014). It is noted that adolescents with IGT and T2D exhibit similar circulating concentrations of total GLP-1 and GIP to adolescents with NGT following an OGTT (Michaliszyn et al., 2014). In terms of incretin response (no effects), data are still controversial in adults. One study showed similar levels of intact GLP-1 and GIP in adults with IGT and T2D compared to NGT following an OGTT (Lee et al., 2010). In contrast, a different study reported that GLP-1 secretion was significantly impaired in adults with T2D vs. NGT (total 2-hour GLP-1 = $16.49 \pm 14.11$ vs. $35.39 \pm 15.40 \mathrm{pmol} / \mathrm{L}, \mathrm{p}<0.005$ ) (Zhang et al., 2012). Furthermore, total 2-hour GLP-1 secretion was positively correlated with the homeostasis model assessment of $\beta$ cell function ( $r=0.186, p<0.0001$ ) (Zhang et al., 2012), testifying an important interplay of incretin hormones and $\beta$ cell function in the evolution of T2D. Collectively, based on studies in adults and limited pediatric evidence, it is postulated that absolute concentrations of GLP-1 and GIP could indicate only a partial segment of the pathophysiological role in T2D, signifying incretin effects function independent of circulating levels.

Given collective evidence on incretins as a key pathophysiological component of T2D, enhancing incretin response and its effects has become a promising target of T2D treatment. In line with this interest/potential, new forms of T2D treatment have targeted GLP-1 receptors. Metformin monotherapy is predominantly used for youthonset T2D (Y-T2D), but incretin mimetic drugs are being added to this therapy to improve glycemic control (Tamborlane et al., 2019). A recent 52-week (26 weeks double blinded and randomly assigned; 26 weeks open label) phase III clinical trial in obese youth with T2D illustrated that a combination of metformin and liraglutide, an incretin mimetic, improved glycemic control (measured by glycated hemoglobin [HbAlc]) at 26 and 52 weeks to a greater extent than metformin treatment alone at 26 and 52 weeks (HbAlc percentage point change from baseline after 26 weeks $=-0.64$ vs. $0.42, p<0.001$, and 52 weeks $=-0.50$ vs. 0.80 [p-value not reported]) (Tamborlane et al., 2019). Additionally, liraglutide has shown potential in adults with longstanding, uncontrolled T2D using highdose insulin; compared to placebo, 6 months of liraglutide treatment improved insulin secretion, measured by area under the curve (AUC) of C-peptide, during a mixed meal challenge, (AUC $C_{C}=1234.6 \pm 588.6$ vs. $922.9 \pm 470.5$ $\mu \mathrm{g} / \mathrm{L} / \mathrm{min}, \mathrm{p}=0.002$ ) (Vanderheiden et al., 2016). Taken together, these studies prove the efficacy of focusing treatment on GLP-1 receptors rather than solely GLP-1 total secretion.

\section{Considerations}

While metformin and insulin were the sole treatment options for Y-T2D prior to FDA approval (in 2019) for the use of GLP-1 agonists, a recent RISE (Restoring Insulin Secretion) clinical trial reported disappointing results that both metformin alone and insulin glargine for three months followed by metformin for nine months were not effective in restoring/preserving $\beta$-cell function in youth with prediabetes and T2D (RISE Consortium \& RISE Consortium Investigators, 2019). On the contrary, the role of GLP-1 and the efficacy of the GLP-1 receptors in T2D signifies a strong target for potential treatment. Additional clinical trials are warranted to see if monotherapy of GLP-1 agonist vs. combined (metformin + liraglutide) therapy is effective to reserve Y-T2D to prediabetes and/or normal state.

Journal of Health Sports \& Kinesiology | ISSN 2692-9864 | www.johsk.com 
More importantly, future research should focus on disease prevention rather than treatment to avoid aggressive complications and metabolic degradations of Y-T2D (RISE Consortium \& RISE Consortium Investigators, 2019). Altogether, it would be germane to investigate whether lifestyle changes (diet, physical activity, exercise medicine) can improve the incretin effect in conjunction with glycemic control in youth.
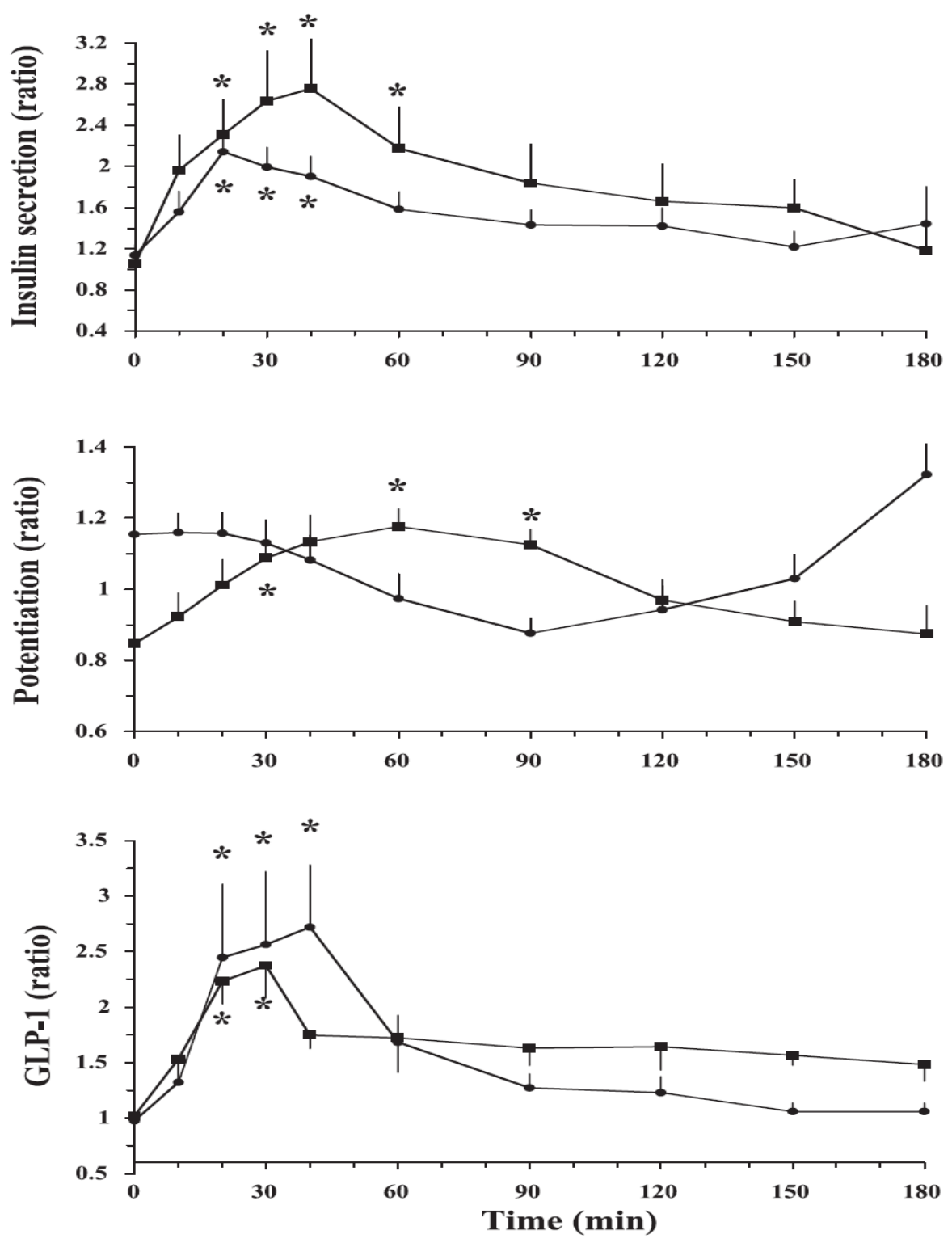

Figure 1. Adopted from Muscelli et al. (2006). Time course of oral-to-IV ratios for insulin secretion rate, potentiation, and GLP-1 in NGT subjects (squares) and IGT subjects (circles). Asterisks denote time points at which mean values differ from baseline (time 0 ) at the level of $P<0.006$.

\section{Journal of Health Sports \& Kinesiology | ISSN 2692-9864 | www.johsk.com}


| 2020 | Volume 1 | Issue 1 | The Journal of Health, Sports, and Kinesiology |

\section{References}

Lee, S., Yabe, D., Nohtomi, K., Takada, M., Morita, R., Seino, Y., \& Hirano, T. (2010). Intact glucagon-like peptide-1 levels are not decreased in Japanese patients with type 2 diabetes. Endocrine Journal, 57(2), 119-126. doi:10.1507/endocrj.K09E-269

Michaliszyn, S. F., Mari, A., Lee, S., Bacha, F., Tfayli, H., Farchoukh, L., ... \& Arslanian, S. (2014). $\beta$-cell function, incretin effect, and incretin hormones in obese youth along the span of glucose tolerance from normal to prediabetes to type 2 diabetes. Diabetes, 63(11), 3846-3855. doi:10.2337/db13-1951

Muscelli, E., Mari, A., Natali, A., Astiarraga, B. D., Camastra, S., Frascerra, S., ... \& Ferrannini, E. (2006). Impact of incretin hormones on $\beta$-cell function in subjects with normal or impaired glucose tolerance. American Journal of Physiology-Endocrinology and Metabolism, 291 (6), E1 144-E1 150. doi:10.1 152/ajpendo.00571.2005

Nauck, M., Stöckmann, F., Ebert, R., \& Creutzfeldt, W. (1986). Reduced incretin effect in type 2 (non-insulindependent) diabetes. Diabetologia, 29(1), 46-52. DOI: 10.1007/BF02427280

RISE Consortium \& RISE Consortium Investigators. (2019). Effects of treatment of impaired glucose tolerance or recently diagnosed type 2 diabetes with metformin alone or in combination with insulin glargine on $\beta$-cell function: Comparison of responses in youth and adults. Diabetes, 68(8), 1670-1680. doi:10.2337/db 19-0299

Tamborlane, W. V., Barrientos-Pérez, M., Fainberg, U., Frimer-Larsen, H., Hafez, M., Hale, P. M., ... \& Rao, P. (2019). Liraglutide in children and adolescents with type 2 diabetes. New England Journal of Medicine, 381 (7), $637-$ 646. doi:10.1056/NEJMoa1903822

Vanderheiden, A., Harrison, L. B., Warshaver, J. T., Adams-Huet, B., Li, X., Yuan, Q., ... \& Pinho, D. F. (2016). Mechanisms of action of liraglutide in patients with type 2 diabetes treated with high-dose insulin. The Journal of Clinical Endocrinology \& Metabolism, 101 (4), 1798-1806. doi:10.1210/jc.2015-3906

Yeow, T. P., Pacini, G., Tura, A., Hor, C. P., Lim, S. L., Tan, F. H. S., .. \& Mohamud, W. N. W. (2017). Preserved glucagonlike peptide-1 responses to oral glucose, but reduced incretin effect, insulin secretion and sensitivity in young Asians with type 2 diabetes mellitus. Bmj Open Diabetes Research and Care, 5(1). doi:10.1136/bmjdrc-2016-000352

Zhang, F., Tang, X., Cao, H., Lü, Q., Li, N., Liu, Y., ... \& An, Z. (2012). Impaired secretion of total glucagon-like peptide1 in people with impaired fasting glucose combined impaired glucose tolerance. International Journal of Medical Sciences, 9(7), 574-581. doi:10.7150/ijms.4128

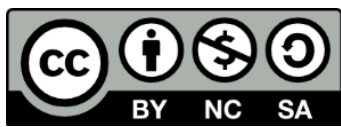

(C) 2020. This work is licensed under a CC BY-NC-SA 4.0 International license. This is an open access article distributed under the Creative Commons Attribution License which permits unrestricted use, distribution, and reproduction in any medium, provided the original work is properly cited.

\section{Journal of Health Sports \& Kinesiology | ISSN 2692-9864 | www.johsk.com}

